\title{
How should we turn data into decisions in AgriFood?
}

Article

Accepted Version

Serazetdinova, L., Garratt, J., Baylis, A., Stergiadis, S., Collison, M. and Davis, S. (2019) How should we turn data into decisions in AgriFood? Journal of the Science of Food and Agriculture, 99 (7). pp. 3213-3219. ISSN 0022-5142 doi: https://doi.org/10.1002/jsfa.9545 Available at https://centaur.reading.ac.uk/81194/

It is advisable to refer to the publisher's version if you intend to cite from the work. See Guidance on citing.

To link to this article DOI: http://dx.doi.org/10.1002/jsfa.9545

Publisher: Wiley

All outputs in CentAUR are protected by Intellectual Property Rights law, including copyright law. Copyright and IPR is retained by the creators or other copyright holders. Terms and conditions for use of this material are defined in the End User Agreement.

\section{www.reading.ac.uk/centaur}

\section{CentAUR}

Central Archive at the University of Reading 
Reading's research outputs online 


\section{Title}

2 How should we turn data into decisions in AgriFood?

\section{Running title}

4 Turning Data into Decisions in AgriFood

\section{Authors}

6 Liliya Serazetdinova, Knowledge Transfer Network; James Garratt, Enviresearch Ltd; Alan

7 Baylis, Nuvistix Innovation Ltd; Sokratis Stergiadis, Animal, Dairy and Food Chain

8 Sciences, School of Agriculture, University of Reading; Martin Collison, Collison and

9 Associates Ltd; Simon Davis, Agrimetrics Ltd.

\section{Abstract}

11 The AgriFood supply chain is under significant pressures related to food security, climate

12 change, and consumer demands for affordable and higher quality food. Various technologies

13 are already deployed producing a large amount of data, which can be utilised to guide

14 decision-making to improve productivity, reduce wastage, and increase traceability across the

15 AgriFood supply chain. Several examples of the use of data are given, including improving

16 efficiency in livestock production, supporting automation and use of robotics in crop

17 production, increasing food safety and evidencing its provenance. The opportunities and

18 ways forward were discussed at a workshop in November 2017, run by the Society of

19 Chemical Industry and the Knowledge Transfer Network in the UK. This paper presents a

20 summary of the key messages from the presentations and focus-group discussions during this event, as interpreted by the authors. A number of challenges in digitalisation of the AgriFood 
supply chain are discussed, such as low inter-operability of different data sets, silo mentality, low willingness to share data and a significant skills gap. Various approaches are presented that could help to unlock the benefits of using data, from practical support to producers and addressing skills gaps, to industrial leadership and the role of government departments and regulatory bodies in leading by example. Looking forward, data are already revolutionising the AgriFood supply chain, however, the benefits will remain piecemeal until the leaders of today are able to bring together the disparate groups into a cohesive whole.

AgriFood, supply chain, Big Data, decision support, Artificial Intelligence (AI), digitalisation

\section{Introduction}

A revolution in food production, processing and distribution is underway ${ }^{1,2,3}$. Various technologies are already transforming the flow of food from field to consumer: technologies such as artificial intelligence (AI), cloud computer processing, remote sensing and robotics. Can these changes benefit the AgriFood supply chain and consumers? If so, how should we move forward? These were the questions addressed in the workshop 'Turning Data into Decisions in AgriFood' hosted by the Society of Chemical Industry (SCI) and the Knowledge Transfer Network (KTN) on 22 November 2017. This workshop brought together 74 professionals to hear about how these technologies are already having an impact and to consider how things might develop in the future. work of Norman Borlaug with plant breeding and nitrogen fertiliser rates led to higher yields,

43 an expansion of irrigation and a rapid increase in mechanisation ${ }^{4}$. 
44 Having enjoyed the benefits of the Green Revolution, we are witnessing the fact that the yield growth this revolution unlocked has stagnated. Between 1985 and 2005, the total global crop production increased by only $28 \%$. Whilst there are still green revolution benefits to be realised, the easy wins have been made. Thus to move forward we have to broaden the scope of the technology we deploy. Digitalisation and big data allows us to do this through enabling much more precise and targeted management of the production process.

This paper summarises the key themes of the workshop leading to an action list for how best to implement the data revolution across production and supply chains.

\section{Drivers of change}

Globally, not only is population growth projected to continue to at least mid-century, but this is combined with a rapidly expanding wealth and consumers adopting a more "westernised diet' rich in protein and demanding cheaper food and increased traceability and provenance. At the same time, the growth of cities means that more sophisticated food supply chains are needed. These mega-trends create a need for greater efficiency and improved data collection, analysis and application have key roles.

The AgriFood sector is a value network, comprising and connecting players within their own sectors, e.g. farmers, various suppliers (machinery, fertiliser, crop protection, etc.), food processors, manufacturers, and retailers. Each component has its own drivers, objectives and issues, which interface with those of connected players and of the whole sector. For example, the importance of data technologies and sharing platforms in the livestock industry is widely recognised and includes a range of applications, such as feed production and quality, animal productivity, health, welfare, breeding and fertility, environmental footprint and product quality, traceability and marketing. 
68 Numerous sensors and connected devices are deployed to help AgriFood companies to collect

69 data related to production, processing and distribution of products, referred to as the Internet of Things (IoT). Software applications with machine learning are required to collect, analyse, and integrate data, connect devices and guide decision-making. Data can help farmers to optimise inputs and adjust land management regimes, which depend on many variables, e.g. soil types, crop varieties and weather. Data can also help suppliers of crop protection products to produce more accurate recommendations, or to gather evidence on their efficacy with more precision, reducing their use and environmental impact.

Examples where the analysis of large volumes of data are benefiting the AgriFood sector are already available. Syngenta made a commitment to the Good Growth Plan and publish datasets on productivity, soil health, biodiversity, compliance with labour standards across their supply chain, etc. ${ }^{6}$. G's Growers, one of the largest producers of salad and vegetables in

80 Europe, integrate agronomic, environmental and operational data to meet daily targets for supply of iceberg lettuces which enables the them to amend production schedules to mitigate against potential shortfalls (G's Growers, personal communication). IMB Research and Mars collaborate to conduct the largest-ever metagenomics study to improve food safety by developing an index of food-borne diseases and minimize the risk ${ }^{7}$. Data are being used to analyse the shopping habits of millions of consumers, to help suppliers develop effective marketing strategies based on purchasing patterns and demographic breakdown ${ }^{8}$.

87 Turning data into decisions is the key for harnessing the power of data. Examples of whole food chain decisions include productivity, finance, insurance, supply chain management, food security, research \& development and environmental stewardship. The recent Global Open

90 Data for Agriculture and Nutrition (GODAN) review ${ }^{3}$ is highly instructive in setting the 
91 context for the data revolution. The authors list a range of potential uses for large data sets in supporting decisions in these areas:

- Early, accurate detection and prediction of problems (pest outbreaks, resistance, water

- What to grow, what treatment to apply and when to plant, treat or harvest

- Risk management (hedging, yields, insurance) and damage control (drought, pests)

- Managing subsidies (funding history, financial data)

- Informing consumers (individuals or companies)

- Fast responses to challenges

100 The GODAN report described key actions required to maximise the use of data in AgriFood

101 supply chains ${ }^{3}$ :

102 - Building trust

- Developing standards and linking data

- Ensuring sustainability

- Providing incentives

- Data publishing principles (e.g. the FAIR principles, a set of guiding principles to make data Findable, Accessible, Interoperable, and Reusable)

108 Similar opportunities and actions were discussed during the event itself and are described

109 later in this paper.

\section{Turning Data into Decisions 2017: summary of the event}

111 In November 2017, SCI and KTN organised the event on Turning Data into Decisions in

112 AgriFood. The purpose of the event was two-fold: firstly, to allow participants to meet each 
113 other and develop their networks, and secondly, to generate discussion on the how this area

114 might develop over the coming years.

115 This event gathered over 70 representatives from crop and livestock agri-businesses, farm

116 and agronomy advisers, precision agriculture companies, machinery and equipment

117 manufacturers, companies developing and using sensors, input manufacturers, food and feed

118 manufacturers, producer organisations, agricultural traders, retail, analytical and

119 measurement services, data analysists, modellers, software engineers, robotics experts,

120 insurance providers, academics, researchers, research councils and government departments.

121 The event covered the following themes:

122 - Why we need data and how to make it meaningful

123 - Examples of data collected from sensors and connected devices, and software

124 applications for data analysis and integration

125 - Data analysis, integration, and the role of machine learning

126 - Use of data for financial models and models related to the environment and climate

127 - Using data for decision-making. e.g. development of software for customer interface

$128 \quad$ and integrating data with AgriFood practice

129 - Data sharing platforms and standards

130 - Governance around data ownership, privacy, and security

131 The morning contained presentations covering example applications of data-driven food

132 production and supply. In the afternoon the audience split into four moderated discussion

133 workshops, each with a chair and rapporteur who took notes (the rapporteurs are listed within

134 the list of authors of this paper). Each of the four workshops considered the above themes in

135 the context of specific stakeholder groups: crop and livestock production, hardware and

136 software developers, or the entire supply chain. Participants in the discussions were 
137 encouraged to share their own examples and use-cases as well as their perspectives on the 138 future.

139 Thus, the opportunities, challenges and action points below are not simply the views of the

140 authors, but an amalgamation of the views of over 70 professionals in this area, as interpreted

141 and brought together by the authors with the context of the cloud of literature that is already

142 available and known use-cases. Many of the conclusions may be found in other sources ${ }^{1,2,3}$.

143 Although our method of collecting data was different from that used by other authors, the

144 themes that emerged were not so different.

146 It is very important to demonstrate that data could drive decision-making in food growing and

147 production with a view to meeting end-customers specifications and satisfaction. Some

148 examples of use of data follow.

150 Variability in meat production systems may result in inefficiencies and reduced business

151 value. Different parameters determine efficiency during each stage of the chain: pre-birth

152 (fertility, gestation length, birth rate); rearing (growth rate, feed conversion ratio, disease

153 resistance, mortality); finishing (weight, yield, fat class); slaughter (abattoir process);

154 processing (butchery, processed meat products); and retail (meat colour, fat content, pack

155 size, price, consumer experience). The fragmented supply chain results in highly variable

156 output. Using data at key points in production, alongside tighter specifications, could help

157 analyse where most value is created and reduce inefficiencies. Sensors enable real-time

158 remote monitoring. An important target is the development of diagnostics and predictive

159 analytics for real-time data-based decision-making to optimise management strategies. A 
160 growing number of professional services for dairy and meat farmers deliver hardware and

161 software applications that can automate data analysis and integrate it into farm management

162 systems and online trading platforms. These big data sets can create value to farmers when

163 incorporated in decision support tools that demonstrate the advantages of using data from

164 various key points that determine efficiency during each stage of the chain. Digital platforms

165 bring buyers and sellers together and enabling vital information to flow up and down the

166 supply chain, enabling proper comparison across multiple key indicators, improving

167 transparency and traceability.

\section{Use of data to support automation and use of robotics}

169 The adoption of robotics in AgriFood is becoming more urgent. Farmers and food

170 manufacturers need to produce more food to higher environmental and quality standards,

171 while experiencing severe labour shortages. Therefore, there is a huge potential in improving

172 productivity through efficiency gains that can be achieved via automation and use of data.

173 The development of 'co-bots', where robots work alongside humans, utilising autonomous or

174 partly autonomous behaviour is a possible option.

175 Robotic systems need data to perceive, make decisions and move. For example, the

176 harvesting process is only partially automated and is relatively inefficient. To automate a

177 process, information may be needed from several machines. To achieve higher levels of

178 automation in harvesting, rule-based systems and modelling can be deployed to optimise

179 process configuration. This can be achieved through the use of data on machine operation and

180 the development of 'training' data sets (Claas KGaA mbH, personal communication).

181 Increasingly, robotic platforms, besides performing manual functions, are used to collect

182 useful in-process data (in-field or during food manufacturing). Data gathered by robotic 
183 systems can be especially valuable due to the ability to capture data repeatedly and

184 consistently from precise locations.

186 Data could help to increase consumer trust and safety by helping to establish the provenance

187 of products and the conditions under which they have been brought to market. Data can help

188 to develop real-time prediction of emerging risks to food safety and fraud, e.g. the horsemeat

189 scandal in 2013. Data on prices of commodities, consumer price index, exchange rates,

190 extreme weather, pest and disease incidents, changes in regulation and standards, profit

191 margins, production capacities, etc. can be used to develop early warning systems for food

192 fraud. Deploying algorithms based on machine learning and statistical methods that aggregate

193 all layers of such data and detect anomalies can collectively highlight any potential issues.

194 Development of shorter supply chains and new operating models

195 Digitalisation is enabling all farmers and food companies, whether small or larger scale to

196 understand consumer needs and target higher value markets. Digital technologies could

197 facilitate development of on-line trading platforms, or virtual online co-ops. These online

198 trading platforms may also help to open-up the food market to smaller farms and food

199 producers allowing them to sell direct and bypass the main existing distribution channels.

200 Differences in purchasing behaviour between different consumer segments may be significant

201 and require special attention to guide business planning, marketing and new product

202 development. Data collected from retailers via consumer membership cards may elucidate

203 factors such as geo-demographics, retail channel and consumer lifestyles. 
205 Inelastic supply and demand in agricultural commodities create volatile prices. Farm

206 businesses succeed or fail on productivity and prices. Historically, mixed farming systems

207 with crops and livestock provided a natural hedge against price falls in any single

208 commodity. As farming modernised and became more capital intensive, most family farms

209 specialised on either cereal farming, or pig farming, etc. to benefit from economies of scale.

210 However, specialisation increased their vulnerability to fluctuating prices. Within the next

211 Common Agricultural Policy (CAP) framework, the development of risk management tools

212 might play a significant role 9 . In the UK, future support to farmers is more likely to be based

213 on environmental land management scheme (i.e. paying farmers for habitat enhancement),

214 replacing current direct payments to farmers in England ${ }^{10}$. Risk management tools might

215 become even more important for UK farmers too. Data analysis can play a significant role in

216 developing new insurance products. Algorithms can be developed to look at the precise

217 correlations between each commodity over time and help to accurately forecast future price

218 risk.

219 Challenges

220 The above examples demonstrated how data are benefiting the AgriFood sector, however,

221 there are still a number of road blocks or difficulties in achieving a wider adoption of

222 digitalisation. These challenges were discussed during the event described above, "Turning

223 Data into Decisions 2017”, and summarised below.

Variety of data types

225 The depth and breadth of data needed to predict events, assess risks accurately and make

226 decisions are huge. Available data form a multi-disciplinary matrix from soil and weather 
227 conditions and animal-related observations to product quality and consumer preferences.

228 Analysing and using such diverse data sets is challenging. Moreover, diverse data sources

229 collated over long periods of time are often needed. This time factor brings potential

230 problems of changing relevance (e.g. crop varieties) and context (e.g. climate change). A

231 further challenge is how to link user experience and qualitative factors so that agricultural

232 decision-making is based on a data driven system.

233

Inter-operability of data sets

234 The potential of connectivity between systems is being constrained by a lack of common data

235 standards or easy-to-use ontologies. Therefore, extraction of value becomes expensive and

236 time-consuming. The collation of data can be very challenging, particularly where

237 management decisions or control systems need inputs from multiple sources. A comparison

238 could be made with the telecoms or air traffic control sector, where very rigorous

239 international standards have existed for many years, defined in terms of both the data format

240 and terminology to allow interoperability.

241 Standardisation of data acquisition and analysis will help to integrate different data sets and

242 create more value. The FAIR principles were first published in $2016^{11}$ and have since been

243 widely adopted, requiring data to be Findable, Accessible, Interoperable, and Re-usable.

244 The GODAN report sets the goal of a 'Global Data Ecosystem', which means amassing varied and pertinent datasets in a way that allows straightforward access to and use of the

246 data. Until recently there has been wide acknowledgement of the potential, but little progress

247 in bringing together fragmented data infrastructures. There is some way to go to ensure that

248 the FAIR principles are at work in the AgriFood sector.

249 It is not clear whether one widely accepted data standard or multiple standards would be more effective. A consistent approach to areas such as data terminology, structure, 
provenance and interoperability could enable better handling and transfer of data across the AgriFood system and develop trust and transparency in the sector. There is a question whether an industry or a government gatekeeper could or should be in place for these 254 standards.

There is a flow of heterogeneous data, information and knowledge through the network of individual sectors that comprise AgriFood, which are traditionally stored in 'silos'. A 'silo mentality' means that the potential to create value from synergies arising from sharing and collaborating is not realised.

This can be attributed to the wide range of people and organisations involved in the supply chain. There are the 'doers' who create, move and process commodities and generate new technological solutions (private companies from start-ups through to international agri-tech companies; farmers from smallholders through to large estates). There are the 'influencers' who set out protocols and standards, provide ethical and legal frameworks and are involved in communication and knowledge transfer (government policy-makers, the media, academic researchers, agricultural advisers); and, in fact, everyone is involved as food consumers.

In order to encourage companies and individuals to collect and exchange data, it is critical to demonstrate its value. Whilst distinct parts of the supply chain (e.g. manufacturers, retailers) have the capacity to invest in research, development and innovation, most benefits from use

271 of data can be accrued at farm level. The evidence of value for the farmer is not yet clear and,

272 consequently, implementation of new technologies, which generate and analyse data is

273 limited. Farmers face significant productivity and profitability challenges, long working

274 hours and often with thin and fluctuating profit margins. When allied to historically free 
access to numerous data sources, this means that many farmers are unclear about the business rationale for investing. This can negate the capacity and enthusiasm for them to invest in

277 innovation and use of data in the first place.

278 The relatively small market and limited marketing opportunities for the services of data 279 generation, organisation and analysis (for example remote sensors feeding data, satellite 280 image analysis software, or agricultural inputs calculator), result in a number of small-scale innovators finding it difficult to secure a sustainable market share. There are many start-ups and technology companies operating in this market, however, $75 \%$ of them lack a visible revenue model ${ }^{12}$.

284 Current uptake tends to focus on larger progressive farms or farms in integrated supply chains

285 which have the financial capacity, interest and in-house staff expertise to take advantage of 286 the data generated. For smaller farms, the business case is seen as being uncertain. The 287 challenge, therefore, is to support key stakeholder groups to realise the value of data, which 288 will enable them to prioritise investment in areas that make the biggest difference to their 289 businesses; and share knowledge with those that do not have the capacity to invest.

291 One of the key barriers to adoption is the accessibility of these technologies to different stakeholders in the AgriFood sector. The skills available to implement and fully exploit the use of data driven technologies is constrained and there is a lack of instructors and teaching

294 resources to deliver appropriate training. There is a need for well-trained operators for 295 complex agricultural machinery which nowadays has not only GPS with machine guidance 296 and automatic steering, but a multitube of additional sensors and software, along with its 297 associated products and services. 
299 As shown above in the example on improving efficiency in livestock production, real-time

300 data-based decision-support tools can help to optimise management strategies and improve

301 efficiency. There is a lack of commercial and widely acknowledged decision support tools

302 that can help to demonstrate the advantages of using big data. In addition, this is limited by

303 willingness to share the data especially when developing decision support tools that span

304 several points in the supply chain.

305 However, it is unclear whether the attitudes of data owners or the lack of opportunities to

306 share are more limiting. There is a fast-developing issue over the ownership of data and

307 liability. A fear of erosion of competitive advantage was one reason suggested for the

308 perceived reluctance to share data. In more collaborative agricultural systems, such as the

309 Netherlands, where farmers and the food chain are focused on collaborating to drive exports,

310 it is more common to share data in benchmarking groups and similar voluntary structures.

311 Sharing of risk and reward in the food chain was a perceived major constraint for many

312 farmers adopting digitalisation as they were afraid that any improvements in performance

313 would be quickly captured by other players in the supply chain. It was felt that the incentive

314 for being an innovator was unclear to many farmers.

315 Trust in data

316 One challenge is to provide industry with the confidence that the technology and data can be

317 trusted. Reliability of data (data quality and integrity - both perceived and actual) is still an

318 issue as the quality control of the mechanisms generating and organising the data may

319 sometimes be questionable. Clear legislation and regulation are essential, but not necessarily

320 in place. 
322 This was another question discussed during the event "Turning Data into Decisions 2017".

323 Over 70 participants worked in different groups to discuss what in needed to make use of data 324 more widespread in the AgriFood sector.

325 The suggestions below are not new in a sense that a number of other papers were published 326 on this subject ${ }^{1,3,12}$. However, the aim of the event was not only to discuss the challenges and

327 the way forward, but also to get a buy in from stakeholders through discussion and facilitate 328 future collaborative working on realising some of these suggestions. This workshop was well

329 represented and the conclusions are well balanced with wide consultation across the 330 community.

332 As data standards become harmonised, there will be greater transparency and understanding

333 of data provenance, quality and integrity. This will help to develop trust and build consensus.

334 Equity

335 It is essential to avoid solutions where the big players get richer and the small players suffer.

336 Those groups who are developing solutions must allow all stages of the supply chain to 'win'.

337 Such solutions will build trust throughout the supply chain and encourage participation in the 338 sharing of data.

\section{Evidence}

340 The investment in data collection and processing will be relatively expensive. In order to

341 avoid waste of resources, there should be a considerable effort in building an evidence-base

342 including an analysis of user needs. In this way, the expected outcomes from the technology

343 will be well aligned with the problems facing the industry. 
344 This paper discusses what opportunities exist to derive value from data and how data could

345 drive decision-making in AgriFood sector. Collecting examples of these "use cases" provides

346 valuable evidence that can help to close the gap between the decision support tools and

347 implementation of big data. Without evidence, there will not be enthusiasm to develop new

348 things. Without new things, there will be no evidence. What should we do first? Bold players

349 have already seen the potential and built some new things, so the evidence should be gathered

350 from what already exists. As the situation develops, there should be a continuing energy in

351 cataloguing and demonstrating what works. This will lead to enhanced storytelling (as

352 discussed below).

353 Regulation

354 Clear legislation and regulation on data privacy, storage, sharing and utilisation, are essential 355 to overcome the barrier of low trust towards data practices. Data must be handled ethically

356 and transparently, with clarification of the role of the owners and handlers of data platforms

357 and defining the exact deliverables and benefits to producers. The conditions (or licensing)

358 for reuse of data need to be clear with rigorous data management and quality assurance ${ }^{3}$.

\section{Reinforcement}

360 Cultural barriers to openness in such a rich and diverse environment remain solid in places.

361 To help to overcome these barriers, it will help if there is positive reinforcement through

362 accreditation, or payment for associated services. Incentives to producers for investing in data

363 collection, analysis and subsequently sharing are required, although these may not be

364 restricted to monetary ones. Other means of reward can be the provision of real-time advice

365 for quick decision-making applications, farm benchmarking and identification of strengths

366 and weaknesses, and/or periodical performance records to assess efficiency. 
368 There should be facilitation of engagement between data producers and partners who have or

369 can develop analytics, visualisation and decision support tools. Innovation in the use of data

370 in AgriFood could be incentivised through competitions and start-up incubation ${ }^{3}$ and greater

371 access to data funded by the taxpayer, e.g. government data.

372

Practical support

373 Capacity should be built across the sector through training, workshops and the development

374 of assets that help people learn how to use relevant data. Such support should cover:

375 developing good practices; guidelines, workflows and tools for publishing and linking data;

376 making the process of data sharing easy and well supported ${ }^{3}$.

\section{Long-term commitment}

378 There should be appropriate support to help organisations sustain their data resources,

379 services and capabilities, ideally bringing private resources in line with public e-

380 infrastructure. The sustainability of services will depend on brokering either government or

381 private sector ongoing support ${ }^{3}$.

382 Storytelling

383 To promote engagement, there needs to be a high visibility of example and success stories

384 involving data in AgriFood. All channels should be explored, for example: government links;

385 advisory organisations; the media; farmers' co-operatives; academic institutes; and related

386 industries ${ }^{3}$. A crucial role is to help organisations working on complementary efforts be

387 aware of each other, as well as providing gap analysis on missing initiatives (an area in which

388 SCI and the KTN are attempting to add value through the publication of this paper). 
390 There is a significant role for government departments and regulatory bodies to lead by

391 example. UK has already taken steps to coordinate the appropriate developments. Initially,

392 several UK Government Departments published the 'UK Strategy for Agricultural

393 Technologies ${ }^{\text {,13 }}$, leading to the formation of Agrimetrics, the Agri-Tech Centre driving

394 ground-breaking solutions from a range of valuable data sources influencing how we

395 produce, supply and ultimately consume food. In another example, the UK Food Standards

396 Agency (FSA) uses data to identify and addressing food safety risks, and applies legislative

397 and non-legislative tools to influence business behaviour in the interests of consumers and

398 working closely with the food industry. Their portal ${ }^{14}$ holds a range of valuable data about

399 food and food safety including food hygiene ratings, allergy alerts, food contaminants and

400 residues, novel foods and GM labelling, animal welfare incidents etc., all of which can be

401 used without charge by any external organisations to add value to their business and by

402 consumers to guide decision-making.

\section{Industrial leadership}

404 In the UK, there are organisations and initiatives such as the Open Data Institute, the FSA,

405 Agrimetrics and the Digital Systems Catapult providing leadership and direction. The 'Made

406 Smarter Review', led by Professor Juergen Maier, supported by over 200 organisations across

407 the UK, provided analysis of the benefits of digitalisation across all sectors of the UK

408 economy ${ }^{15}$. "Made Smarter" identified that digital technologies offer the potential for

409 substantial gains in UK food chain productivity (on p. 155 there is a reference to

410 "Digitalisation will secure the future of food supply chains"). The review also identified that

411 in some technology areas the UK is already a global leader e.g. food and refrigeration

412 monitoring systems via IoT, food safety and traceability systems, with the potential to unite 
413 UK food sector expertise with UK IoT and block chain expertise to create globally leading

414 disruptive technologies.

416 The "Turning Data into Decisions in AgriFood" meeting in November 2017 had a UK focus,

417 but the problems and solutions are common to other countries. The European Commission is

418 providing a framework for developing actionable plans to support digitalisation in industry,

419 such as the Digitising European Industry initiative (DEI), which produced sector specific

420 plans for how digitalisation could add value in various industry sectors, including one for

421 AgriFood. DEIs vision for the future is one of increased connectivity and interoperability

422 between platforms, whereby more services could be provided through gathering and

423 combining information from a wide range of smaller platforms gathering data from sensors,

424 machinery, animals, etc. This would increase resilience within farming, e.g. to manage

425 resource efficiency, health and welfare of animals, and it could also be used to decrease

426 bureaucracy for farmers ${ }^{16}$. Examples of other international initiatives include those led by

427 Wageningen University and Research (Netherlands) ${ }^{1,2,17}$, INRA (France) ${ }^{18}$, Agroknow

428 (Greece and Belgium) ${ }^{19}$, and AgGateway (USA) ${ }^{20}$. International organisations and initiatives supporting the digitalisation of AgriFood sector include GODAN, CGIAR, and FAO (with a dedicated Interest Group on Agricultural Data).

\section{Forward look}

432 The above measures and activities open opportunities for specialist data integration and data analysis business that can help to "fine-tune" data delivery channels, customise data delivery to various customers, develop new business models, shorten supply chains, develop new services and products, and give more control to food producers and customers. These actions can change the balance of power in the AgriFood supply chain. 
437 The future will be bright if the power of private-sector innovation and idea generation can be 438 harnessed with public-sector support and in a form of public-private partnerships. The 439 challenges are similar in all sectors of AgriFood (e.g. resistance to technology uptake, data

440 kept in silos, inconsistent standards) and there are similarities in the underlying solutions

441 across sectors. Data-driven agriculture feeds into many societal agendas, such as

442 sustainability, climate-change responses, food pricing and rural economic development. The

443 UK has already taken steps to coordinate the appropriate developments and outlined the 444 actions that need to be taken ${ }^{15}$.

445 The Data Revolution is underway, we already use data, but in a piecemeal and fragmented 446 way. The real benefits will not be realised until the leaders of today are able to bring together 447 the disparate groups into a cohesive whole.

\section{Acknowledgments}

449 The authors would like to thank SCI and KTN for organising the event on 22 November 2017 450 at SCI Headquarters in London, and speakers and discussion leaders for providing material 451 discussed in this publication.

452 Glossary

454 Massive volumes of probably complex data acquired in real time from diverse sources subjected to powerful and innovative modelling and analysis to create valuable information.

457 The use of a network of remote servers hosted on the Internet, which provide a shared pool of 458 computer resources to store, manage and process data. 
460 Usually software-based interactive systems using specific and often diverse data to make

461 evidence-based recommendations to help users make better decisions.

462 Digitalisation

463 Enabling, improving and/or transforming systems and operations by leveraging digital

464 technologies and a wider use of digitised data to create valuable information.

465 Internet of things

466 The connections via the Internet of computers and sensors embedded in machines and other

467 devices allowing the collection and exchange of data.

468 Machine learning

469 The ability of computers and the devices they control to autonomously and continuously

470 improve their capabilities as a result of data they collect and process.

471 Open data

472 Data that anyone can access, use, modify and store free of charge, but subject to attributing

473 sources and preserving openness.

474 Remote sensing

475 The detection and/or identification of objects or landscapes from various distances without

476 direct contact. 
478

479

480

481

482

483

484

485

486

487

488

489

490

491

492

493

494

495

496

497

498

499

1. Wolfert S, Gea L, Verdouw C, Bogaardt MJ. Big Data in Smart Farming - A review. Agricultural Systems 153: 69-80. https://doi.org/10.1016/j.agsy.2017.01.023

2. van Evert FK, Fountas S, Jakovetic D, Crnojevic V, Travlos I and Kempenaar C. Big Data for weed control and crop protection. Weed Research 57: 218-233.

\section{https://doi.org/10.1111/wre.12255}

3. GODAN (2016). A Global Data Ecosystem for Agriculture and Food, Allemang D and Teegarden B. Available from: http://www.godan.info/documents/data-ecosystemagriculture-and-food [Cited 2018 May 17].

4. Borlaug N. The Green Revolution, Peace, and Humanity. Nobel Lecture, December 11, 1970. Available from:

\section{https://www.nobelprize.org/nobel_prizes/peace/laureates/1970/borlaug-lecture.html} [Cited 2018 August 08].

5. Foley JA, Ramankutty N, Brauman KA, Cassidy ES, Gerber JS, Johnston M, Mueller ND, O'Connell C, Ray DK, West PC, Balzer C, Bennett EM, Carpenter SR, Hill J, Monfreda C, Polasky S, Rockström J, Sheehan J, Siebert S, Tilman D, Zaks DP. Solutions for a cultivated planet. Nature 478, 337-342.

\section{https://doi.org/10.1038/nature10452}

6. Syngenta. Good Growth Plan Open Data. Available from: https://www.syngenta.com/what-we-do/the-good-growth-plan [Cited 2018 December 04].

7. IBM. IMB Research and Mars, Inc. launch pioneering effort to drive advances in global food safety. Press release 29 Jan 2015. Available from: https://www03.ibm.com/press/us/en/pressrelease/45938.wss\#release [Cited 2018 December 04]. 
8. Donnelly C, Simmons G, Armstrong G, Fearne A. Digital loyalty card 'big data' and small business marketing: Formal versus informal or complementary? International Small Business Journal 33: 422-442. https://doi.org/10.1177/0266242613502691

9. European Parliamentary Research Service. Briefing July 2016, Price volatility in agricultural markets: risk management and other tools. Available from: http://www.europarl.europa.eu/RegData/etudes/BRIE/2016/586609/EPRS_BRI(2016)586609_EN .pdf [Cited 2018 September 18].

10. HM Government. A Green Future: Our 25 Year Plan to Improve the Environment (2018). Available from: https://assets.publishing.service.gov.uk/government/uploads/system/uploads/attachment_data/file/ 693158/25-year-environment-plan.pdf [Cited 2018 September 18].

11. Wilkinson M, Dumontier M, Aalbersberg I, Appleton G, Axton M, Baak A, Blomberg N, Boiten JW, da Silva Santos LB, Bourne PE, Bouwman J, Brookes AJ, Clark T, Crosas M, Dillo I, Dumon O, Edmunds S, Evelo CT, Finkers R, Gonzalez-Beltran A, Gray AJ, Groth P, Goble C, Grethe JS, Heringa J, 't Hoen PA, Hooft R, Kuhn T, Kok R, Kok J, Lusher SJ, Martone ME, Mons A, Packer AL, Persson B, Rocca-Serra P, Roos M, van

Thompson M, van der Lei J, van Mulligen E, Velterop J, Waagmeester A, Wittenburg P, management and stewardship. Scientific Data 3:160018 https://doi.org/10.1038/sdata.2016.18.

12. PA Consulting. Transforming agriculture with data-driven insights (published $19 \mathrm{Feb}$ 2018). Available from: https://www.paconsulting.com/insights/2018/digitalagriculture/ [Cited 2018 May 17]. 
524 13. HM Government. A UK Strategy for Agricultural Technologies (2013). Available from: https://www.gov.uk/government/publications/uk-agricultural-technologies-strategy [Cited 2018 May 17].

14. Food Standards Agency. Open Data platform. Available from: https://data.food.gov.uk/catalog/datasets?keyword=fhrs [Cited 2018 September 11].

15. UK Government. Made Smarter, Industrial Digitalisation Review (2017). Available from: https://www.gov.uk/government/publications/made-smarter-review [Cited 2018 May 17].

16. European Union. Digitalising European Industry. Working Group 2 Digital Industrial Platforms (2017). Available from:

$534 \quad$ May 17].

535

17. Akkerweb. Farm Management Information System, Stichting Akkerweb, Apeldoorn, Netherlands. Available from: https://akkerweb.eu/en-gb/ [Cited 2018 May 17].

18. European Commission. SmartCow: an integrated infrastructure for increased research capability and innovation in the European cattle sector. Description of the Horizon 2020 project, 1 February 2018 till 31 March 2022. Available from: https://cordis.europa.eu/project/rcn/212581_en.html [Cited 2018 May 17].

19. eROSA project webpage. Available from: http://www.erosa.aginfra.eu/ [Cited 2018 May 17].

20. AgGateway project webpage. Available from: http://www.aggateway.org/Home.aspx. [Cited 2018 May 17]. 